\title{
Socio-Demographic Determinants of Health-Related Quality of Life in Tehran Lipid and Glucose Study (TLGS)
}

\author{
Sara Jalali-Farahani, ${ }^{1}$ Parisa Amiri, ${ }^{1,}$ Sepideh Bakht, ${ }^{1}$ Zeinab Shayeghian, ${ }^{1}$ Leila Cheraghi, ${ }^{2}$ and \\ Fereidoun Azizi ${ }^{3}$ \\ ${ }^{1}$ Research Center for Social Determinants of Health, Research Institute for Endocrine Sciences, Shahid Beheshti University of Medical Sciences, Tehran, Iran \\ ${ }^{2}$ Department of Biostatistics and Epidemiology, Research Institute for Endocrine Sciences, Shahid Beheshti University of Medical Sciences, Tehran, Iran \\ ${ }^{3}$ Endocrine Research Center, Research Institute for Endocrine Sciences, Shahid Beheshti University of Medical Sciences, Tehran, Iran \\ "Corresponding author: Parisa Amiri, Research Center for Social Determinants of Health, Research Institute for Endocrine Sciences, Shahid Beheshti University of Medical \\ Sciences, P.O. Box: 19395-4763, Tehran, IR Iran. Tel: +98-2122432500, Fax: +98-2122402463, E-mail: amiri@endocrine.ac.ir
}

Received 2017 February 12; Revised 2017 June 18; Accepted 2017 August 30.

\begin{abstract}
Background: Health-related quality of life (HRQOL) is a multi-dimensional concept that is affected by different variables. A large body of evidence shows that socio-demographic factors have a significant influence on HRQOL. When considering differences in cultural contexts and social values of various countries and the lack of evidence regarding socio-demographic determinants of HRQOL among the Iranian general population, it is important to verify the main socio-demographic determinants of HRQOL in an urban Iranian population.

Objectives: This study aimed to explore socio-demographic factors associated with HRQOL and to ascertain the determinants of poor HRQOL in participants of the Tehran lipid and glucose study (TLGS).

Methods: The participants included 3491 adults, aged $\geq 20$ years, who had participated in the TLGS. To obtain socio-demographic and HRQOL information, participants were interviewed by trained interviewers. Mean HRQOL scores were compared using the student's t test and analysis of variance(ANOVA). To determine significant determinants of poor HRQOL, multivariate logistic regression analysis was performed.

Results: Mean ages of males and females were $47.7 \pm 15.6$ and $47.8 \pm 14.2$ years, respectively and $58.6 \%$ of participants were male. Males had significantly higher scores compared to females in both the physical and mental domains of $\mathrm{HRQOL}(\mathrm{P}<0.001)$. In males, significant determinants of poor physical HRQOL were older age, being married, being unemployed yet having other sources of income, having literacy levels below high school diploma, and having chronic diseases $(\mathrm{P}<0.05)$. In females, however older age and being housewives were significant determinants of poor physical HRQOL $(\mathrm{P}<0.05)$. In addition, significant determinants of poor mental HRQOL were younger age and being single or divorced/widowed in males and younger age and being illiterate as well as having literacy levels below high school diploma in females $(\mathrm{P}<0.05)$.

Conclusions: Current findings highlight the importance of socio-demographic determinants of HRQOL in both genders, specifically in the physical domain, and demonstrate their roles to be more prominent in males. These findings highlight gender-specific associations between socio-demographic factors and various aspects of HRQOL among the TLGS population, which could be applied in future research focusing on non-communicable diseases and planning health promotion programs.
\end{abstract}

Keywords: Health-Related Quality of Life, Socio-Demographic Factors, Chronic Diseases, Adults, Iran

\section{Background}

Health-related quality of life (HRQOL), a subjective perception of individuals about their health condition, is defined as "a multi-dimensional concept that encompasses the physical, emotional, and social components associated with an illness or treatment" (1). It could be used as an indicator of health status of a population and serve as a beneficial tool, which reflects the performance of health systems (2). Moreover, measuring HRQOL could be applied in comparing HRQOL of patients with different diseases or comparing the effects of different treatments and inter- ventions (3). Several factors have the potential to influence how individuals perceive and report their health status; among them, social factors could play an important role in the conception of individuals regarding their health status.

A huge amount of data report several sociodemographic factors, such as age (4-6), gender (4-9), level of literacy $(4-6,10,11)$, education $(8,12)$, marital status $(6,8,12)$, and the individual's income $(7,10-12)$, to be significantly associated with HRQOL. Many countries share similarities, although they differ in other contexts, such as history, cultural values, funding and organiza- 
tion, living styles, distribution of income and delivery of health care, which may influence the impact of sociodemographic factors on health perception of individuals. Moreover, definitions of health differ in various cultures and countries focus on different health concerns based on their health promotion priorities. Aforementioned issues accompanied by differences in health care programs and social welfare policies in various countries could influence the perception of individuals regarding their health status; therefore, social values and cultural context should be considered in HRQOL studies and social determinants of HRQOL need to be identified in each country. As mentioned before, the associations between socio-demographic factors and HRQOL have been investigated thoroughly in general populations worldwide. Yet, a few studies have been conducted regarding this issue in Iran $(4,9,13)$, and those documented have limitations in generalizability and their populations were limited to certain cities, i.e. Bandar Abbas and Zahedan or specific age ranges, e.g. among the elderly ( $\geq 65$ years). Hence, there is a lack of evidence regarding sociodemographic determinants of HRQOL among the general population of Tehran.

Tehran lipid and glucose study (TLGS) is an ongoing prospective study initiated in 1998 with the aim of determining the prevalence of non-communicable diseases and identifying their corresponding risk factors. While social determinants of health have been found to be factors influencing the self-perception of individuals regarding their health status (4-12), there is lack of evidence regarding HRQOL and its associated socio-demographic factors in the TLGS population as a large sample of the general population of Tehran. Additionally, since sociodemographic factors may potentially confound the associations between HRQOL and related factors, it is necessary to identify the socio-demographic factors that may affect the findings of future studies in this population. Therefore, this study aimed at investigating the association between socio-demographic factors and HRQOL in adult participants of the TLGS, which would also provide the chance of future cross-cultural comparisons of social determinants of perceived health status of different populations.

\section{Methods}

In the current study, the data of participants of TLGS was used. The TLGS, an ongoing community-based study, was designed and conducted to determine the risk factors and prevent non-communicable diseases among residents of district 13 of Tehran. The study had 2 main parts, including cross-sectional and prospective phases. The crosssectional phase aimed at determining the prevalence of coronary artery disease (CAD) and its associated risk factors (1999-2001), and the prospective interventional study aimed at improving healthy lifestyles and preventing noncommunicable disease (NCD) risk factors. This study was initiated in 2002 and was designed to continue for the next 20 years. Using a multistage stratified cluster random sampling method, a total of 15005 individuals, aged over 3 years were selected. Assessments were performed at the beginning of the study and were designed to be repeated every 3 years. Details of the study have been published previously $(14,15)$. Participants of the current study were recruited from adults, aged $\geq 20$ years, which participated during years 2014 to 2015 and had complete data on HRQOL. The current study was approved by the ethics committee of the research institute for endocrine sciences of Shahid Beheshti University of Medical Sciences (Code: i3ECRIES93/11/26). All participants signed written informed consent forms prior to data collection.

Trained interviewers completed socio-demographic information data sheet, including age, marital status, level of education, and employment status. Participants were classified to 3 age groups, including young adults (20 to 40 years), middle aged ( 41 to 60 years), and the elderly ( $\geq 61 \mathrm{y}$ ). Marital status was categorized to single, married, and divorced/widowed groups. Furthermore, level of education was categorized as illiterate, below high school diploma, high school diploma, undergraduate degree, and postgraduate degree. Additionally, based on their employment status, participants were categorized in 4 groups, including unemployed, employed, unemployed yet having other sources of income and last, students. Having chronic diseases was defined as diagnosed cancer, chronic kidney diseases, diabetes, hypertension, and history of cardiovascular diseases.

Data on HRQOL was collected using the Iranian version of the short-form 12-item health survey version 2 (SF-12v2). Findings of the validity study of SF-12v2 conducted among Iranians indicated it to be a reliable and valid measure of HRQOL among the studied population (16). The SF-12v2 is a generic measure of perceived health status, which includes 12 items, encompassing 8 subscales, including physical functioning ( 2 items), role physical ( 2 items), bodily pain (1 item), general health ( 1 item), vitality ( 1 item), social functioning ( 1 item), role emotional ( 2 items), and mental health (2 items). The scores of 8 subscales ranged from 0 to 100 , where a zero score indicates the lowest level and 100 indicates the highest level of health measured by the scale. Poor HRQoL was defined as the first quartile of physical component summary (PCS) and mental component summary (MCS) scores.

Data was analyzed using the statistical package for social sciences (SPSS, version 20). Continuous and categorical 
variables were reported as mean (standard deviation) and frequency (percentage), respectively. The HRQOL scores were compared using the Student's t test and analysis of variance (ANOVA). To determine significant determinants of poor HRQOL, first, logistic regression analysis was performed for each variable, then variables with P values $<0.2$ were entered in the multivariate logistic regression analysis and corresponding odds ratios (ORs) of each variable for poor HRQOL were reported. A P value of less than 0.05 was considered to be statistically significant.

\section{Results}

Participants were 3491 adults ( $58.5 \%$ male) with mean ages of $47.7 \pm 15.6$ and $47.8 \pm 14.2$ years, for males and females, respectively. Distribution of the socio-demographic characteristics of participants is presented in Table 1. The highest proportions of participants were from middle age group (41.9\%), followed by young adults (32.5\%) and the elderly (25.6\%). Most participants were married $(81.0 \%$ of males and $75.9 \%$ of females). Levels of education of $31.8 \%$ of participants were below high school diploma, $38.1 \%$ of them had high school diploma, and the remaining (33.4\% of males and $27.8 \%$ of females) had academic degrees. Most males were employed (67.3\%) and most females were housewives (68.8\%). Over half of the males (57.0\%) and half the females (50.5\%) had chronic diseases. Means of HRQOL scores in males and females are presented in Table 2; in all subscales of HRQOL, males had significantly higher scores $(\mathrm{P}<0.001)$ compared to females.

Since there were gender differences in HRQOL scores, the association between socio-demographic factors and HRQOL scores were analyzed separately in males and females. Table 3 indicates HRQOL scores by different socio-demographic characteristics and chronic diseases in males. The results show that in males, age groups, marital status, and education were socio-demographic factors significantly associated with both PCS scores and MCS scores. In addition, chronic diseases were also significantly associated with PCS in males, whereas in females, all sociodemographic factors and chronic diseases were significantly associated with PCS, while none of the aforementioned factors had a significant association with MCS (Table 4).

Using multiple logistic regression analysis, factors associated with poor HRQOL were determined (Table 5). In males, significant determinants of poor HRQOL in PCS, included older age, being married, being unemployed yet having other sources of income, having literacy levels below high school diploma, and having chronic diseases, whereas in females, older age and being housewives were significant determinants of PCS. In addition, younger age and being single or divorced/widowed in males and younger age and being illiterate as well as having education levels below high school diploma in females were significant determinants of poor MCS.

\section{Discussion}

This study explored socio-demographic factors associated with health-related quality of life as well as determinants of poor HRQOL in an urban Iranian population. Findings of this study show gender differences in HRQOL scores. Moreover, most socio-demographic factors and having chronic diseases were significantly associated with HRQOL.

Findings of this study showed that both age and gender were associated with HRQOL. In the current study, in both males and females, the highest mean for PCS scores was reported by young adults followed by middle age and elderly groups, however, an opposite trend was observed for MSC; these findings were in agreement with previous studies conducted in other countries $(6,12)$. Recent findings imply that the interventions aimed at improving HRQOL among Iranian adults should target different aspects of health, depending on the age group. To further clarify, considering the current findings, interventions should focus on physical health in the elderly, whereas in young adults, interventions should address mental rather than physical problems in both genders. In addition, in the current study, females reported lower HRQOL scores compared to males; these findings were in line with those of previous studies conducted in other countries $(5,8,12)$ and in an Iranian population $(4,9)$, and may be due to the tendency of females to rate their well-being lower than males (17).

Based on the current findings, marital status was another determinant of HRQOL. Previous findings indicate that the relationship between marital status and HRQOL differs with age and gender (18). In the current study, PCS in both genders and MCS, only in males, were significantly different amongst single, married, and divorced/widowed groups. In the regression model, considering all sociodemographic factors and chronic diseases, marital status was the only significant determinant of poor HRQOL in males, but not in females. However, this association followed different patterns in PCS and MCS. Single and divorced/widowed males were less likely to report poor HRQOL in PCS compared to the married group; however, single and divorced/widowed groups were 2 and 8 folds more likely to report poor MCS, compared to married males; these findings were similar to those observed in previous studies (6). The reason underlying lower OR for reporting poor PCS in single and divorced/widowed males, 
Table 1. Distribution of Socio-Demographic Characteristics and Prevalence of Chronic Diseases in the Study Population

\begin{tabular}{|c|c|c|c|c|}
\hline & Total $(n=3491)$ & $\operatorname{Men}(n=2044)$ & Women $(n=1447)$ & P Value \\
\hline Age groups n (\%) & & & & $<0.05$ \\
\hline Young adults (20 - 40 years) & $1135(32.5)$ & $464(32.1)$ & $671(32.8)$ & \\
\hline Middle age ( 41 - 60 years) & $1462(41.9)$ & $581(40.2)$ & $881(43.1)$ & \\
\hline Elderly ( $\geq 61)$ & $894(25.6)$ & $402(27.8)$ & $492(24.1)$ & \\
\hline Marital status n (\%) & & & & $<0.001$ \\
\hline Single & $481(13.8)$ & $249(17.2)$ & $232(11.4)$ & \\
\hline Married & $2717(78.0)$ & $1170(81.0)$ & $1547(75.9)$ & \\
\hline Divorced & $57(1.6)$ & $15(1.0)$ & $42(2.1)$ & \\
\hline Widowed & $227(6.5)$ & $11(0.8)$ & $216(10.6)$ & \\
\hline Level of education $n$ (\%) & & & & $<0.001$ \\
\hline Illiterate & $97(2.8)$ & $19(1.3)$ & $78(3.8)$ & \\
\hline Below high school diploma & $1012(29.0)$ & $370(25.6)$ & $642(31.4)$ & \\
\hline High school diploma & $1327(38.1)$ & $572(39.6)$ & $755(37.0)$ & \\
\hline Undergraduate degree & $881(25.3)$ & $389(27.0)$ & $492(24.1)$ & \\
\hline Postgraduate degree & $168(4.8)$ & $93(6.4)$ & $75(3.7)$ & \\
\hline Job status n (\%) & & & & $<0.001$ \\
\hline Unemployed/housewife & $1453(41.7)$ & $47(3.3)$ & $1406(68.8)$ & \\
\hline Unemployed, but had other sources of income & $601(17.3)$ & $365(25.4)$ & $236(11.5)$ & \\
\hline Student & $136(3.9)$ & $58(4.0)$ & $78(3.8)$ & \\
\hline Employed & $1292(37.1)$ & $968(67.3)$ & $324(15.9)$ & \\
\hline Chronic diseases n (\%) & & & & $<0.001$ \\
\hline No & $1754(53.2)$ & $780(57.0)$ & $974(50.5)$ & \\
\hline Yes & $1545(46.8)$ & $589(43.0)$ & $956(49.5)$ & \\
\hline
\end{tabular}

compared to their married counterparts in the current study, is not clear and needs to be investigated in future research; one possible explanation could be related to the quality of marriage as it has been documented that marital quality is associated with health (19) and its related indices, such as negative spousal behaviors, have been found to be correlated with poorer physical health (20). Hence, in assessing the association between marital status and healthrelated indices, the marital quality and quality of relationships between spouses should also be considered.

In terms of education, in the current study, mean scores of physical HRQOL had an increasing trend according to level of education in both genders. Findings of the regression model indicated that only males with literacy levels below high school diploma were more likely to report poor physical HRQOL compared to their counterparts, who had academic degrees. However, in females, both illiterate and those who had literacy levels below high school diploma were more likely to report poor mental HRQOL, compared to their counterparts with academic degrees. In line with our findings, previous studies in other countries $(10,11,21)$ and in Iran $(4,9,22)$ reported that higher levels of education were associated with better HRQOL. Also, similar to our findings, the association between education and HRQOL varied by gender in a previous study (23). The association between higher education and better HRQOL may be due to increasing possibilities of obtaining better jobs, which meant higher incomes and greater access to health care and other resources and consequently better health status.

In terms of employment status, in males, employed individuals and students had higher physical HRQOL scores compared to their unemployed counterparts, statistically significant in some subscales. Amongst females, students and employed individuals had higher HRQOL scores compared to housewives and those who were unemployed, yet had other sources of income in all physical and mental subscales, except for the emotional role subscale. The cur- 
Table 2. Mean and Standard Deviations of Health-Related Quality of Life Scores in Males and Females

\begin{tabular}{lccc}
\hline & Men & Women & PValue \\
\hline Physical functioning & $87.7 \pm 22.7$ & $78.2 \pm 27.8$ & $<0.001$ \\
\hline Role physical & $84.0 \pm 21.9$ & $71.8 \pm 25.3$ & $<0.001$ \\
\hline Bodily pain & $84.4 \pm 21.4$ & $73.1 \pm 25.9$ & $<0.001$ \\
General health & $49.6 \pm 22.8$ & $44.8 \pm 22.9$ & $<0.001$ \\
\hline Vitality & $68.7 \pm 25.4$ & $59.1 \pm 27.1$ & $<0.001$ \\
\hline Social function & $83.3 \pm 24.6$ & $76.4 \pm 27.6$ & $<0.001$ \\
\hline Role emotional & $79.5 \pm 21.8$ & $69.4 \pm 24.8$ & $<0.001$ \\
Mental health & $74.2 \pm 20.5$ & $65.1 \pm 22.8$ & $<0.001$ \\
\hline
\end{tabular}

Table 3. Mean Health-Related Quality of Life (HRQOL) Scores in Males by Socio-Demographic Characteristics and Having Chronic Diseases ${ }^{\mathrm{a}}$

\begin{tabular}{|c|c|c|c|c|c|c|c|c|c|c|}
\hline & $\begin{array}{c}\text { Physical } \\
\text { Functioning }\end{array}$ & Role Physical & Bodily pain & General Health & PCS & Vitality & Social Function & Role Emotional & Mental Health & MCS \\
\hline \multicolumn{11}{|l|}{ Age groups (y) } \\
\hline $20 \cdot 40$ & $92.7 \pm 17.7^{\mathrm{b}}$ & $86.3 \pm 18.2^{\mathrm{b}}$ & $85.5 \pm 18.9$ & $58.5 \pm 21.8^{b}$ & $52.5 \pm 6.3^{\mathrm{b}}$ & $69.1 \pm 23.8$ & $81.2 \pm 24.7^{\mathrm{b}}$ & $74.6 \pm 21.9^{\mathrm{b}}$ & $71.7 \pm 20.4^{\mathrm{b}}$ & $47.8 \pm 10.6^{b}$ \\
\hline $41-60$ & $88.3 \pm 21.8$ & $83.4 \pm 22.3$ & $82.8 \pm 21.5$ & $47.4 \pm 21.4$ & $49.1 \pm 7.4$ & $69.8 \pm 23.9$ & $83.3 \pm 24.2$ & $80.1 \pm 21.3$ & $74.5 \pm 19.9$ & $50.6 \pm 9.7$ \\
\hline$\geq 61$ & $80.9 \pm 26.9$ & $82.2 \pm 24.8$ & $85.6 \pm 23.8$ & $42.7 \pm 22.7$ & $47.2 \pm 8.9$ & $66.8 \pm 29.1$ & $85.8 \pm 24.8$ & $84.3 \pm 21.1$ & $76.5 \pm 21.2$ & $52.3 \pm 9.6$ \\
\hline \multicolumn{11}{|l|}{ Marital status } \\
\hline Married & $86.3 \pm 23.8$ & $83.3 \pm 22.5$ & $83.9 \pm 22.2$ & $47.2 \pm 22.3$ & $48.8 \pm 7.9$ & $68.9 \pm 25.4$ & $84.2 \pm 23.8$ & $81.0 \pm 21.3$ & $75.4 \pm 20.3$ & $51.0 \pm 9.7$ \\
\hline $\begin{array}{l}\text { Di- } \\
\text { vorced/widon }\end{array}$ & $83.7 \pm 27.3$ & $85.6 \pm 25.2$ & $86.5 \pm 22.6$ & $51.9 \pm 27.3$ & $51.5 \pm 11.2$ & $62.5 \pm 34.1$ & $70.2 \pm 40.0$ & $76.9 \pm 23.6$ & $60.1 \pm 26.9$ & $44.5 \pm 11.7$ \\
\hline \multicolumn{11}{|l|}{ Level of education } \\
\hline Illiterate & $80.3 \pm 29.6^{b}$ & $76.3 \pm 36.5$ & $88.2 \pm 25.5$ & $42.1 \pm 27.7^{b}$ & $47.2 \pm 10.8^{b}$ & $60.5 \pm 37.6$ & $89.5 \pm 20.9$ & $79.6 \pm 30.4^{\mathrm{b}}$ & $73.7 \pm 33.6$ & $50.8 \pm 13.6^{\mathrm{b}}$ \\
\hline $\begin{array}{l}<\text { High } \\
\text { school } \\
\text { diploma }\end{array}$ & $82.6 \pm 26.4$ & $82.5 \pm 24.1$ & $84.2 \pm 23.7$ & $41.4 \pm 22.9$ & $47.2 \pm 8.3$ & $67.0 \pm 29.1$ & $84.8 \pm 25.6$ & $83.3 \pm 21.6$ & $76.9 \pm 21.7$ & $52.1 \pm 9.9$ \\
\hline $\begin{array}{l}\text { High } \\
\text { school } \\
\text { diploma }\end{array}$ & $88.0 \pm 21.6$ & $84.7 \pm 21.4$ & $83.8 \pm 21.9$ & $49.8 \pm 22.3$ & $49.9 \pm 7.8$ & $69.3 \pm 24.4$ & $82.6 \pm 24.6$ & $78.3 \pm 21.9$ & $73.2 \pm 20.4$ & $49.7 \pm 10.2$ \\
\hline $\begin{array}{l}\text { Under- } \\
\text { graduate } \\
\text { degree }\end{array}$ & $90.9 \pm 20.4$ & $84.2 \pm 20.4$ & $84.9 \pm 19.2$ & $55.5 \pm 21.1$ & $51.1 \pm 6.9$ & $70.2 \pm 23.5$ & $82.4 \pm 24.3$ & $77.6 \pm 21.6$ & $73.3 \pm 19.4$ & $49.3 \pm 10.1$ \\
\hline $\begin{array}{l}\text { Postgrad- } \\
\text { uate } \\
\text { degree }\end{array}$ & $93.3 \pm 16.5$ & $86.9 \pm 17.6$ & $86.0 \pm 17.1$ & $58.6 \pm 21.0$ & $52.1 \pm 6.3$ & $68.3 \pm 19.6$ & $84.7 \pm 21.2$ & $79.3 \pm 18.2$ & $73.5 \pm 17.1$ & $49.4 \pm 8.6$ \\
\hline \multicolumn{11}{|l|}{ Job status } \\
\hline $\begin{array}{l}\text { Unem- } \\
\text { ployed/house }\end{array}$ & $86.7 \pm 18.7^{b}$ & $82.2 \pm 22.1^{\mathrm{b}}$ & $82.9 \pm 20.3$ & $43.6 \pm 23.0^{\mathrm{b}}$ & $49.6 \pm 6.5$ & $60.6 \pm 29.8^{b}$ & $73.4 \pm 30.1^{b}$ & $73.9 \pm 25.4^{\mathrm{b}}$ & $67.3 \pm 21.9$ & $45.9 \pm 11.7$ \\
\hline $\begin{array}{l}\text { Unem- } \\
\text { ployed, } \\
\text { but had } \\
\text { other } \\
\text { sources of } \\
\text { income }\end{array}$ & $79.6 \pm 27.9$ & $79.3 \pm 26.8$ & $83.2 \pm 25.6$ & $42.4 \pm 22.2$ & $46.4 \pm 9.3$ & $64.4 \pm 28.8$ & $84.5 \pm 25.5$ & $83.3 \pm 21.8$ & $75.7 \pm 21.7$ & $51.9 \pm 10.0$ \\
\hline Student & $97.8 \pm 9.7$ & $83.8 \pm 23.3$ & $85.8 \pm 17.6$ & $62.5 \pm 20.0$ & $53.2 \pm 6.3$ & $72.4 \pm 22.8$ & $81.5 \pm 26.3$ & $74.8 \pm 23.7$ & $73.3 \pm 21.8$ & $48.3 \pm 12.2$ \\
\hline No & $90.7 \pm 19.6^{\mathrm{c}}$ & $85.4 \pm 20.2^{C}$ & $84.1 \pm 20.4$ & $54.0 \pm 22.7^{\mathrm{C}}$ & $50.9 \pm 7.4^{\mathrm{C}}$ & $68.9 \pm 23.9$ & $82.8 \pm 24.3$ & $78.1 \pm 21.8^{\mathrm{C}}$ & $73.3 \pm 19.8$ & $49.4 \pm 10.1$ \\
\hline Yes & $83.2 \pm 25.5$ & $82.0 \pm 24.1$ & $84.5 \pm 23.1$ & $42.8 \pm 21.7$ & $47.7 \pm 8.0$ & $67.9 \pm 27.3$ & $84.3 \pm 24.6$ & $81.8 \pm 21.5$ & $75.5 \pm 21.3$ & $51.5 \pm 9.8$ \\
\hline
\end{tabular}


Table 4. Mean Health-Related Quality of Life (HRQOL) Scores in Females by Socio-Demographic Characteristics and Having Chronic Diseases ${ }^{\mathrm{a}}$

\begin{tabular}{|c|c|c|c|c|c|c|c|c|c|c|}
\hline & $\begin{array}{l}\text { Physical } \\
\text { Functioning }\end{array}$ & Role Physical & Bodily Pain & General Health & PCS & Vitality & Social Function & Role Emotional & Mental Health & MCS \\
\hline \multicolumn{11}{|l|}{ Age groups (y) } \\
\hline $20-40$ & $88.6 \pm 21.0^{\mathrm{b}}$ & $78.8 \pm 21.9^{\mathrm{b}}$ & $77.8 \pm 22.8^{\mathrm{b}}$ & $54.9 \pm 22.9^{\mathrm{b}}$ & $50.4 \pm 7.3^{b}$ & $61.7 \pm 24.6^{\mathrm{b}}$ & $77.5 \pm 25.1$ & $68.1 \pm 23.5$ & $68.0 \pm 20.3^{b}$ & $45.6 \pm 10.4$ \\
\hline $41-60$ & $76.9 \pm 27.6$ & $70.9 \pm 24.7$ & $72.4 \pm 25.2$ & $43.1 \pm 21.9$ & $45.9 \pm 8.9$ & $59.0 \pm 27.3$ & $75.8 \pm 27.9$ & $69.7 \pm 24.9$ & $64.5 \pm 22.3$ & $46.2 \pm 11.3$ \\
\hline$\geq 61$ & $66.5 \pm 30.9$ & $64.0 \pm 27.9$ & $67.9 \pm 29.7$ & $33.9 \pm 18.7$ & $42.0 \pm 9.4$ & $55.9 \pm 29.7$ & $75.8 \pm 30.2$ & $70.9 \pm 26.4$ & $62.2 \pm 26.3$ & $47.0 \pm 12.4$ \\
\hline \multicolumn{11}{|l|}{ Marital status } \\
\hline Married & $78.1 \pm 27.8$ & $71.2 \pm 25.3$ & $72.2 \pm 25.5$ & $43.8 \pm 22.3$ & $46.1 \pm 9.0$ & $58.8 \pm 27.1$ & $76.2 \pm 27.9$ & $69.6 \pm 24.7$ & $65.1 \pm 22.7$ & $46.3 \pm 11.3$ \\
\hline $\begin{array}{l}\text { Di- } \\
\text { vorced/widow }\end{array}$ & $69.9 \pm 30.7$ & $66.9 \pm 27.9$ & $69.9 \pm 30.1$ & $38.4 \pm 20.9$ & $43.8 \pm 9.6$ & $57.5 \pm 29.8$ & $76.7 \pm 28.6$ & $69.2 \pm 26.2$ & $62.7 \pm 25.5$ & $46.5 \pm 12.2$ \\
\hline \multicolumn{11}{|l|}{ Level of education } \\
\hline Illiterate & $59.3 \pm 35.4^{\mathrm{b}}$ & $63.8 \pm 32.7^{\mathrm{b}}$ & $62.2 \pm 36.9^{b}$ & $34.6 \pm 21.0^{b}$ & $41.7 \pm 10.5^{b}$ & $49.4 \pm 32.9^{\mathrm{b}}$ & $66.7 \pm 35.3^{b}$ & $66.2 \pm 29.4^{\mathrm{b}}$ & $52.7 \pm 28.3^{b}$ & $43.0 \pm 13.5$ \\
\hline $\begin{array}{l}<\text { High } \\
\text { school } \\
\text { diploma }\end{array}$ & $70.7 \pm 29.4$ & $65.7 \pm 26.3$ & $70.3 \pm 26.9$ & $35.6 \pm 20.8$ & $43.5 \pm 9.1$ & $55.7 \pm 29.4$ & $74.8 \pm 29.8$ & $69.2 \pm 25.9$ & $62.8 \pm 24.6$ & $46.2 \pm 12.1$ \\
\hline $\begin{array}{l}\text { High } \\
\text { school } \\
\text { diploma }\end{array}$ & $79.9 \pm 26.8$ & $73.3 \pm 24.2$ & $73.2 \pm 25.1$ & $45.9 \pm 22.6$ & $47.1 \pm 8.8$ & $60.2 \pm 26.6$ & $76.7 \pm 26.8$ & $68.3 \pm 24.9$ & $65.3 \pm 22.1$ & $45.9 \pm 11.1$ \\
\hline $\begin{array}{l}\text { Under- } \\
\text { graduate } \\
\text { degree }\end{array}$ & $87.3 \pm 22.2$ & $77.9 \pm 22.4$ & $77.2 \pm 23.5$ & $54.1 \pm 21.5$ & $49.6 \pm 7.9$ & $62.8 \pm 23.6$ & $79.1 \pm 24.7$ & $71.1 \pm 22.3$ & $69.1 \pm 19.9$ & $46.9 \pm 10.0$ \\
\hline $\begin{array}{l}\text { Postgradu- } \\
\text { ate } \\
\text { degree }\end{array}$ & $86.0 \pm 19.8$ & $79.0 \pm 20.8$ & $79.3 \pm 20.7$ & $59.0 \pm 19.9$ & $49.9 \pm 7.9$ & $64.3 \pm 21.4$ & $79.0 \pm 22.9$ & $75.5 \pm 22.7$ & $70.0 \pm 18.9$ & $48.0 \pm 11.1$ \\
\hline \multicolumn{11}{|l|}{ Job status } \\
\hline $\begin{array}{l}\text { Unem- } \\
\text { ployed/houser }\end{array}$ & $76.9 \pm 28.3^{\mathrm{b}}$ & $70.3 \pm 25.7^{\mathrm{b}}$ & $71.5 \pm 26.5^{b}$ & $42.9 \pm 22.7^{\mathrm{b}}$ & $45.7 \pm 9.1^{\mathrm{b}}$ & $57.7 \pm 27.8^{b}$ & $75.3 \pm 28.7^{b}$ & $68.9 \pm 25.2$ & $64.7 \pm 23.1$ & $46.0 \pm 11.4$ \\
\hline $\begin{array}{l}\text { Unem- } \\
\text { ployed, } \\
\text { but had } \\
\text { other } \\
\text { sources of } \\
\text { income }\end{array}$ & $71.2 \pm 30.5$ & $68.0 \pm 26.8$ & $69.4 \pm 28.5$ & $37.6 \pm 18.9$ & $43.5 \pm 9.3$ & $60.7 \pm 27.8$ & $77.3 \pm 27.6$ & $71.3 \pm 25.5$ & $64.9 \pm 25.7$ & $47.7 \pm 12.2$ \\
\hline Student & $91.0 \pm 16.6$ & $83.9 \pm 17.1$ & $83.0 \pm 18.2$ & $61.2 \pm 21.2$ & $52.7 \pm 5.2$ & $63.5 \pm 23.7$ & $79.5 \pm 21.6$ & $67.2 \pm 22.4$ & $69.2 \pm 18.6$ & $45.4 \pm 10.1$ \\
\hline No & $83.9 \pm 24.2^{\mathrm{C}}$ & $75.5 \pm 23.4^{c}$ & $74.9 \pm 24.1^{\mathrm{C}}$ & $49.9 \pm 22.5^{\mathrm{C}}$ & $48.4 \pm 8.2^{\mathrm{C}}$ & $60.4 \pm 25.6$ & $77.7 \pm 25.9$ & $68.9 \pm 23.7$ & $66.5 \pm 20.9^{c}$ & $45.9 \pm 10.6$ \\
\hline Yes & $72.2 \pm 30.2$ & $68.2 \pm 26.5$ & $70.9 \pm 27.5$ & $38.9 \pm 21.9$ & $44.3 \pm 9.6$ & $58.1 \pm 28.5$ & $75.4 \pm 29.0$ & $70.2 \pm 25.6$ & $63.8 \pm 24.6$ & $46.6 \pm 11.9$ \\
\hline
\end{tabular}

rent findings also showed that being a housewife was significantly associated with poor physical HRQOL in females. The current findings support those of a previous study conducted in the south-east of Iran, which reported higher HRQOL scores in mental components among employed females, compared to housewives (13). Another study also reported better HRQOL scores in employed individuals compared to their unemployed and inactive counterparts (12). Findings of Nevada's 2009 Behavioral Risk Factor Surveillance System (BRFSS) also indicated that unemployed individuals reported worse perceived mental health and they were more likely to delay health care services due to cost, compared to the labor force and employed participants (24). One of the underlying reasons for higher HRQOL in employed individuals, compared to unemployed ones, may be due to access to more resources, which means greater health care access; another, may be due to an unhealthy lifestyle, such as drinking, smoking and sedentary behavior among unemployed individuals, compared to employed ones, which may contribute to the higher rates of poor physical health.

The current findings indicate significantly poorer physical HRQOL scores in both males and females with chronic diseases compared to their healthy counterparts; however, considering all the socio-demographic determinants of poor HRQOL, only males, but not females, with chronic diseases were significantly more likely to report poor PCS. These findings were consistent with previous studies, which report poorer HRQOL in individuals with different chronic diseases, such as diabetes, hypertension 
Table 5. Odds Ratios and 95\% Confidence Intervals for Poor HRQOL Among Males and Females

\begin{tabular}{|c|c|c|c|c|}
\hline & \multicolumn{2}{|l|}{ PCS } & \multicolumn{2}{|l|}{ MCS } \\
\hline & Odds Ratio (95\% CI) & $\mathbf{P}$ & Odds Ratio $(95 \% \mathrm{CI})$ & $\mathbf{P}$ \\
\hline & \multicolumn{4}{|c|}{ Males } \\
\hline $\operatorname{Age}(y)$ & $1.020(1.001-1.040)$ & 0.035 & $0.972(0.954-0.991)$ & 0.003 \\
\hline \multicolumn{2}{|l|}{ Marital status (ref, married) } & 0.002 & & $<0.001$ \\
\hline Single & $0.398(0.202-0.784)$ & 0.008 & $2.176(1.147-4.129)$ & 0.017 \\
\hline Divorced/widowed & $0.276(0.093-0.820)$ & 0.021 & $7.950(2.088-30.267)$ & 0.002 \\
\hline \multicolumn{2}{|l|}{ Job status (ref, employed) } & 0.062 & & 0.119 \\
\hline Unemployed/housewife & $2.297(0.831-6.344)$ & 0.109 & $1.752(0.654-4.690)$ & 0.264 \\
\hline Student & $0.528(0.109-2.563)$ & 0.428 & $0.377(0.142-0.999)$ & 0.050 \\
\hline Unemployed, but had other sources of income & $1.790(1.051-3.049)$ & 0.032 & $1.204(0.743-1.951)$ & 0.450 \\
\hline \multicolumn{2}{|l|}{ Education (ref, Postgraduate degree) } & 0.036 & & 0.803 \\
\hline Illiterate & $1.454(0.318-6.641)$ & 0.629 & $0.711(0.166-3.04)$ & 0.646 \\
\hline$<$ High school diploma & $2.821(1.329-5.988)$ & 0.007 & $0.771(0.358-1.661)$ & 0.507 \\
\hline High school diploma & $1.752(0.873-3.515)$ & 0.114 & $0.974(0.473-2.006)$ & 0.943 \\
\hline Undergraduate degree & $1.437(0.696-2.964)$ & 0.327 & $1.015(0.479-2.148)$ & 0.969 \\
\hline Chronic diseases (ref, no) & $1.713(1.156-2.540)$ & 0.007 & $1.103(0.755-1.612)$ & 0.613 \\
\hline \multirow[t]{2}{*}{ Constant } & 0.168 & 0.001 & 3.558 & 0.020 \\
\hline & \multicolumn{4}{|c|}{ Females } \\
\hline $\operatorname{Age}(y)$ & $1.061(1.044-1.079)$ & $<0.001$ & $0.977(0.962-0.992)$ & 0.002 \\
\hline \multicolumn{2}{|l|}{ Marital status (ref, married) } & 0.155 & - & - \\
\hline Single & $0.548(0.276-1.087)$ & 0.085 & - & - \\
\hline Divorced/widowed & $0.744(0.407-1.359)$ & 0.336 & - & - \\
\hline \multicolumn{2}{|l|}{ Job status (ref, employed) } & 0.117 & & 0.532 \\
\hline Unemployed/housewife & $1.718(1.031-2.862)$ & 0.038 & $0.852(0.556-1.308)$ & 0.465 \\
\hline Student & $0.622(0.134-2.896)$ & 0.545 & $0.905(0.332-2.468)$ & 0.845 \\
\hline Unemployed, but had other sources of income & $1.823(0.893-3.725)$ & 0.099 & $0.656(0.371-1.162)$ & 0.148 \\
\hline \multicolumn{2}{|l|}{ Education (ref, Postgraduate degree) } & 0.277 & & 0.001 \\
\hline Illiterate & $0.880(0.284-2.725)$ & 0.824 & $6.230(2.303-16.852)$ & $<0.001$ \\
\hline$<$ High school diploma & $1.373(0.530-3.559)$ & 0.514 & $2.947(1.302-6.674)$ & 0.010 \\
\hline High school diploma & $0.978(0.398-2.402)$ & 0.961 & $1.995(0.923-4.309)$ & 0.079 \\
\hline Undergraduate degree & $0.830(0.344-2.005)$ & 0.679 & $1.347(0.636-2.850)$ & 0.437 \\
\hline Chronic diseases (ref, no) & $0.969(0.684-1.372)$ & 0.858 & $0.950(0.687-1.312)$ & 0.754 \\
\hline Constant & 0.035 & $<0.001$ & 1.777 & 0.202 \\
\hline
\end{tabular}

Abbreviations: MCS, mental component summary; PCS, physical component summary.

and kidney disease, compared to their healthy counterparts (25-28) and more chronic conditions were shown to be associated with greater negative effects on HRQOL (29). Similarly, results of previous studies conducted among Iranian populations are in agreement with this finding (30, 31).
This study had a number of limitations that should be mentioned. First, since the sample of the current study was limited to residents of Tehran metropolitan city, its findings cannot be generalized to broader communities, such as other Iranian cities or rural areas. Second, owing to the cross-sectional design of the current study, causal infer- 
ences about the association between socio-demographic factors and HRQOL cannot be made. Another limitation of the study is social desirability bias, which may be due to collecting HRQOL data via interviewers. Despite the mentioned limitations, this study had a large sample size. Moreover, with data collected using one of the most common instruments used for assessing HRQOL of the general population (SF-12), facilitating the comparison of the current findings with other countries, is another strength of this study.

Based on current findings, except for age, which was a significant determinant of poor physical and mental HRQOL in both genders, in males, though all sociodemographic factors as well as chronic diseases were significant determinants of poor physical HRQOL, only marital status significantly affected poor mental HRQOL. In females, only job status and education were significant determinants of poor HRQOL in physical and mental aspects, respectively. These findings highlighted genderspecific associations between socio-demographic factors and various aspects of HRQOL among the TLGS population, which could be applied in future research focusing on noncommunicable diseases and planning health promotion programs.

\section{Acknowledgments}

The authors wish to acknowledge Ms. Niloofar Shiva for critical editing of English grammar and syntax of the manuscript.

\section{References}

1. Revicki DA. Health-related quality of life in the evaluation of medical therapy for chronic illness. J Fam Pract. 1989;29(4):377-80. [PubMed: 2677212].

2. Romero M, Vivas-Consuelo D, Alvis-Guzman N. Is Health Related Quality of Life (HRQoL) a valid indicator for health systems evaluation? Springerplus. 2013;2:664. doi: 10.1186/2193-1801-2-664. [PubMed: 24353981].

3. Ahmed S, Berzon RA, Revicki DA, Lenderking WR, Moinpour CM, Basch E, et al. The use of patient-reported outcomes (PRO) within comparative effectiveness research: implications for clinical practice and health care policy. Med Care. 2012;50(12):1060-70. doi: 10.1097/MLR.ob013e318268aaff. [PubMed: 22922434].

4. Aghamolaei T, Tavafian SS, Zare S. Determinants of health related quality of life on people living in bandar abbas, iran. Iran J Public Health. 2011;40(3):128-35. [PubMed: 23113095].

5. Pappa E, Kontodimopoulos N, Papadopoulos AA, Niakas D. Assessing the socio-economic and demographic impact on health-related quality of life: evidence from Greece. Int J Public Health. 2009;54(4):241-9. doi: 10.1007/s00038-009-8057-x. [PubMed: 19424661].

6. Song T, Ding YW, Sun Y, He YN, Qi DJ, Wu Y, et al. A population-based study on health-related quality of life among urban community residents in Shenyang, Northeast of China. BMC Public Health. 2015;15:921. doi: 10.1186/s12889-015-2238-8. [PubMed: 26386951].
7. Pappa E, Chatzikonstantinidou S, Chalkiopoulos G, Papadopoulos A, Niakas D. Health-Related Quality of Life of the Roma in Greece: The Role of Socio-Economic Characteristics and Housing Conditions. Int J Environ Res Public Health. 2015;12(6):6669-81. doi: 10.3390/ijerph120606669. [PubMed: 26075724].

8. Prause W, Saletu B, Tribl GG, Rieder A, Rosenberger A, Bolitschek J, et al. Effects of socio-demographic variables on health-related quality of life determined by the quality of life index-German version. Hum Psychopharmacol. 2005;20(5):359-65. doi: 10.1002/hup.699. [PubMed: 15981308].

9. Tajvar M, Arab M, Montazeri A. Determinants of health-related quality of life in elderly in Tehran, Iran. BMC Public Health. 2008;8:323. doi: 10.1186/1471-2458-8-323. [PubMed: 18808675].

10. Lahana E, Pappa E, Niakas D. The impact of ethnicity, place of residence and socioeconomic status on health-related quality of life: results from a Greek health survey. Int J Public Health. 2010;55(5):391400. doi: 10.1007/s00038-010-0171-2. [PubMed: 20652355].

11. Ma X, McGhee SM. A cross-sectional study on socioeconomic status and health-related quality of life among elderly Chinese. BMJ Open. 2013;3(2) doi: 10.1136/bmjopen-2012-002418. [PubMed: 23377996].

12. Kivits J, Erpelding ML, Guillemin F. Social determinants of healthrelated quality of life. Rev Epidemiol Sante Publique. 2013;61 Suppl 3:S189-94. doi:10.1016/j.respe.2013.06.001. [PubMed: 23849946].

13. Saravi FK, Navidian A, Rigi SN, Montazeri A. Comparing health-related quality of life of employed women and housewives: a cross sectional study from southeast Iran. BMC Womens Health. 2012;12:41. doi: 10.1186/1472-6874-12-41. [PubMed: 23173572].

14. Azizi F, Rahmani M, Emami H, Mirmiran P, Hajipour R, Madjid M, et al. Cardiovascular risk factors in an Iranian urban population: Tehran lipid and glucose study (phase 1). Soz Praventivmed. 2002;47(6):40826. [PubMed: 12643001].

15. Azizi F, Ghanbarian A, Momenan AA, Hadaegh F, Mirmiran P, Hedayati $M$, et al. Prevention of non-communicable disease in a population in nutrition transition: Tehran Lipid and Glucose Study phase II. Trials. 2009;10:5. doi: 10.1186/1745-6215-10-5. [PubMed:19166627].

16. Montazeri A, Vahdaninia M, Mousavi SJ, Asadi-Lari M, Omidvari S Tavousi M. The 12-item medical outcomes study short form health survey version 2.0 (SF-12v2): a population-based validation study from Tehran, Iran. Health Qual Life Outcomes. 2011;9:12. doi:10.1186/1477-75259-12. [PubMed: 21385359].

17. Prus SG. Comparing social determinants of self-rated health across the United States and Canada. Soc Sci Med. 2011;73(1):50-9. doi: 10.1016/j.socscimed.2011.04.010. [PubMed: 21664020].

18. Han KT, Park EC, Kim JH, Kim SJ, Park S. Is marital status associated with quality of life? Health Qual Life Outcomes. 2014;12:109. doi: 10.1186/s12955-014-0109-0. [PubMed: 25104276].

19. Robles TF, Slatcher RB, Trombello JM, McGinn MM. Marital quality and health: a meta-analytic review. Psychol Bull. 2014;140(1):140-87. doi: 10.1037/a0031859. [PubMed: 23527470].

20. Bookwala J. The role of marital quality in physical health during the mature years. J Aging Health. 2005;17(1):85-104. doi: 10.1177/0898264304272794. [PubMed: 15601785].

21. Mielck A, Reitmeir P, Vogelmann M, Leidl R. Impact of educational level on health-related quality of life (HRQL): results from Germany based on the EuroQol 5D (EQ-5D). Eur J Public Health. 2013;23(1):45-9. doi: 10.1093/eurpub/ckr206. [PubMed: 22434205].

22. Baheiraei A, Bakouei F, Mohammadi E, Montazeri A, Hosseni M. The Social Determinants of Health in Association with Women's Health Status of Reproductive Age: A Population-Based Study. Iran J Public Health. 2015;44(1):119-29. [PubMed: 26060783].

23. Regidor E, Barrio G, de la Fuente L, Domingo A, Rodriguez C, Alonso J Association between educational level and health related quality of life in Spanish adults. J Epidemiol Community Health. 1999;53(2):75-82. [PubMed: 10396467].

24. Pharr JR, Moonie S, Bungum TJ. The impact of unemployment on mental and physical health, access to health care and health risk behaviors. ISRN Public Health; 2011. 
25. Trevisol DJ, Moreira LB, Kerkhoff A, Fuchs SC, Fuchs FD. Health-related quality of life and hypertension: a systematic review and metaanalysis of observational studies. J Hypertens. 2011;29(2):179-88. doi: 10.1097/HJH.ob013e328340d76f. [PubMed: 21045726].

26. Spiegel BM, Melmed G, Robbins S, Esrailian E. Biomarkers and healthrelated quality of life in end-stage renal disease: a systematic review. Clin J Am Soc Nephrol. 2008;3(6):1759-68. doi: 10.2215/CJN.00820208. [PubMed: 18832106].

27. Grandy S, Fox KM, Shield Study Group . Change in health status (EQ5D) over 5 years among individuals with and without type 2 diabetes mellitus in the SHIELD longitudinal study. Health Qual Life Outcomes. 2012;10:99. doi: 10.1186/1477-7525-10-99. [PubMed: 22917219].

28. Megari K. Quality of Life in Chronic Disease Patients. Health Psychol
Res. 2013;1(3):27. doi: 10.4081/hpr.2013.e27. [PubMed: 26973912].

29. Heyworth IT, Hazell ML, Linehan MF, Frank TL. How do common chronic conditions affect health-related quality of life? $\mathrm{Br} J \mathrm{Gen}$ Pract. 2009;59(568):353-8. doi: 10.3399/bjgp09X453990. [PubMed: 19656444].

30. Kiadaliri AA, Najafi B, Mirmalek-Sani M. Quality of life in people with diabetes: a systematic review of studies in Iran. J Diabetes Metab Disord. 2013;12(1):54. doi: 10.1186/2251-6581-12-54. [PubMed: 24354933].

31. Yaghoubi A, Tabrizi JS, Mirinazhad MM, Azami S, Naghavi-Behzad M, Ghojazadeh M. Quality of life in cardiovascular patients in iran and factors affecting it: a systematic review. J Cardiovasc Thorac Res. 2012;4(4):95-101. doi: 10.5681/jcvtr.2012.024. [PubMed: 24250995]. 